\title{
Pathologic mitoses and pathology of mitosis in tumorigenesis
}

\author{
R.G. Steinbeck \\ Department of Oncology and Pathology, Karolinska Institute and Hospital, 17176 Stockholm, \\ Sweden
}

Key words: aberrant mitosis, asymmetry, cancerogenesis, cell cycle, chromosome division figure, genome stability

\section{HISTORY}

The gist of my hypothesis (.. is) a certain abnormal chromatin constitution. Each process, which brings about this chromatin constitution, would result in the origin of a malignant tumour. Certainly, I consider irregularities with mitosis as the normal mode of the origin of an incorrectly assembled nucleus. This statement by Boveri (1914) has considered earlier observations of asymmetric divisions in human cancers (Hansemann, 1890). The hypothesis is based on the understanding of mitosis as an equational bipartition of the hereditary substance (Flemming, 1879; Roux, 1883). Latest since it was known that genes are located on chromosomes (Sturtevant, 1913), their balanced transport in anaphase appeared as a condition of correct somatic proliferation. True mitoses guarantee the constancy of terminally differentiated tissues. Politzer (1934) has performed $\mathrm{X}$-ray experiments to investigate abnormal karyokinesis with regard to anomalous chromatin condensation, chromosome breakage, spindle malformation, and failure in cytokinesis. On the basis of light microscopy, further significant progress in understanding the pathology of mitosis was not possible. Tumour cases with reduced chromosome numbers seduced to the idea that mitotic activity is rather under cytoplasmic than under nuclear control (Koller, 1947).

Advance in the Hansemann-Boveri hypothesis depended on insights in the structure of DNA and its genetic implications. Further prerequisites were the determination of the correct number of elements in the human karyotype (Tjio and Levan, 1956) as well as safe chromosome identification by technical banding (Caspersson et al., 1970). The use of microscope photometers allowed measurements of DNA content in interphase nuclei (Caspersson et al., 1955; Deeley, 1955; see also for a recent review van der Ploeg, 2000). The technique was eased with the Feulgen procedure that produced a DNA specific dye for visible light. Microphotometry has found an early application in cancer research (Atkin and Richards, 1956; Sandritter and Fischer, 1962). Olle Caspersson (1964) was one of the first who focussed on premalignant lesions and thus on tumorigenesis. Quantitative DNA records revealed an interrelation between genomic alterations and tumorigenesis. The global recording of nuclear DNA became an important approach towards quantification of genome stability. A congruence and causal connection has been suggested for the scattered profiles of DNA content in interphase nuclei and the countable aneuploidy in metaphase spreads (Richards and Atkin, 1960). Two unfortunate mainstreams have hampered progress in the immediate study of pathologic mitoses. One was the desire for rash sample analysis that favoured the use of flow fluorometers, which are limited to interphase nuclei from disintegrated tissues. Another hindrance were statements that the use of microsections is not permissible in microphotometry (Böcking, 1998). On the other hand, a legitimate caveat has been proposed that judgements of histopathologists upon mitosis may be unreliable because of interobserver variability. Therefore, Barry et al. (2001) have called for a robust definition of abnormal mitoses.

Correspondence to: R.G. Steinbeck

Email: imp1kiel@aol.com 


\section{PATHOLOGIC MITOSES}

The human body is the result of mitotic proliferation in accordance with cellular diversification. Adult tissues consist mainly of specialized cells, which are terminally differentiated. Mitotic activity remains restricted to somatic stem cells that eventually repair injuries, and to committed stem cells that substitute for tissue turnover. There are three criteria that characterize aberrations from regular mitotic activity in the soma: (1) dislocated divisions with relentless persistency, (2) multipolar anaphase distortion and (3) aberrant DNA content. Each can be traced with methods using light microscopy.

\section{Divisions in tissue disorder}

Healthy mucous membranes, as an example, are composed of four compartments consisting of (1) silent stem cells, (2) a layer of committed cells showing controlled proliferation, (3) differentiated cells and (4) cells scheduled for apoptosis. Proper mitoses must not occur in the maturely differentiated compartment. Even a heavy inflammation does not violate this rule (Fig. 1 a). Positional and temporal limitations of mitotic activity provide evidence for stringent genetic control.

Divisions appearing outside the committed compartment, however, are highly suspicious for being pathologic. If an illegitimate proliferation is not stopped soon, the environment becomes less differentiated and eroded by time. Diagnostic antibodies may provide further evidence for dislocated cell multiplication (Ki67 expression) and lagging differentiation (no decoration for E-cadherin). Cellular divisions are strictly limited in time for some days after injuries. Long persistence of cell multiplication indicates cell cycle disorders followed by aberrant mitotic figures, which occur already in premalignant lesions (Fig. 1 b). This rule was proven in squamous epithelia of oral mucosa, esophagus, uterine cervix and skin, further in columnar epithelia of gastric and colorectal mucosae (Steinbeck, 1997; Steinbeck and Auer, 2000; Khaled et al., 2000).

\section{Multipolar chromosome arrangements}

Centrioles usually are observed paired in a distinct cytoplasmic body, the centrosome. The autoreduplication of centrioles in late G2 of interphase, however, is disturbed when more then two centrosomes result (Galeotti, 1893; Pihan et al., 1998). In consequence of spindle defects, tripolar and tetrapolar metaphases could occur and have been already recorded by Hansemann (1890). Multipolar arrangements are indeed most conspicuous and therefore acknowledged as the paradigm of pathologic mitoses. The dramatic morphology favoured the opinion that they are sure indicators of malignancy (Therman and Timonen, 1950). But with (premalignant) carcinomas in situ of the uterine cervix, Hamperl (1954) has noticed DreiGruppen-Metaphasen, which probably were tripolar structures.

Multipolar spindles would distribute chromosomes at random. Thus, they were judged being highly inefficient in accomplishing segregation of whole genomes (Boveri, 1914; Stern, 1958). If a primary multipolar process could finish successfully through telophase, the progenitors would be extremely hypoploid. Three $1.3 \mathrm{c}$ nuclei should result from a tripolar anaphase, whereas a quadripolar configuration should produce four haploid (1 c) nuclei. In each case, apoptosis is expected to eliminate the pathologic products. The consideration depends on a yet not answered question whether multipolar figures with a regular DNA content of $4.0 \mathrm{c}$ really exist. According to my experience, multipolar structures are hyperchromatic containing more than $4 \mathrm{c}$ DNA.

Multipolar events are rather rare in tumours, and their prophase precursors are unknown. Scarcity explains the lack of molecular data. Multipolar organization shows that the spindle can function independently and ruthlessly against chromosomes and the karyotype. This is especially obvious from experiments when microtubules segregate DNA-coated microballs instead of chromosomes (Zhang and Nicklas, 1996).

\section{Chromosome division figures}

Pathologic divisions occur in premalignant and malignant tumours. Since their defects are not discernible for sure with the light microscope, they are generally addressed as "mitoses" (Fig. 1 d-f). Examples only with extreme aberrations may be realized by mere morphological inspection like the asymmetric telophases reported by Hansemann (1890). Microphotometry provided quantitative evidence that divisions in premalignant and malignant lesions represent indeed pathologic entities despite their unsuspicious morphology (Fig. 2).

Such a division was termed Chromosome Division Figure (CDF) when its DNA content was $\pm 0.5 \mathrm{c}$ 

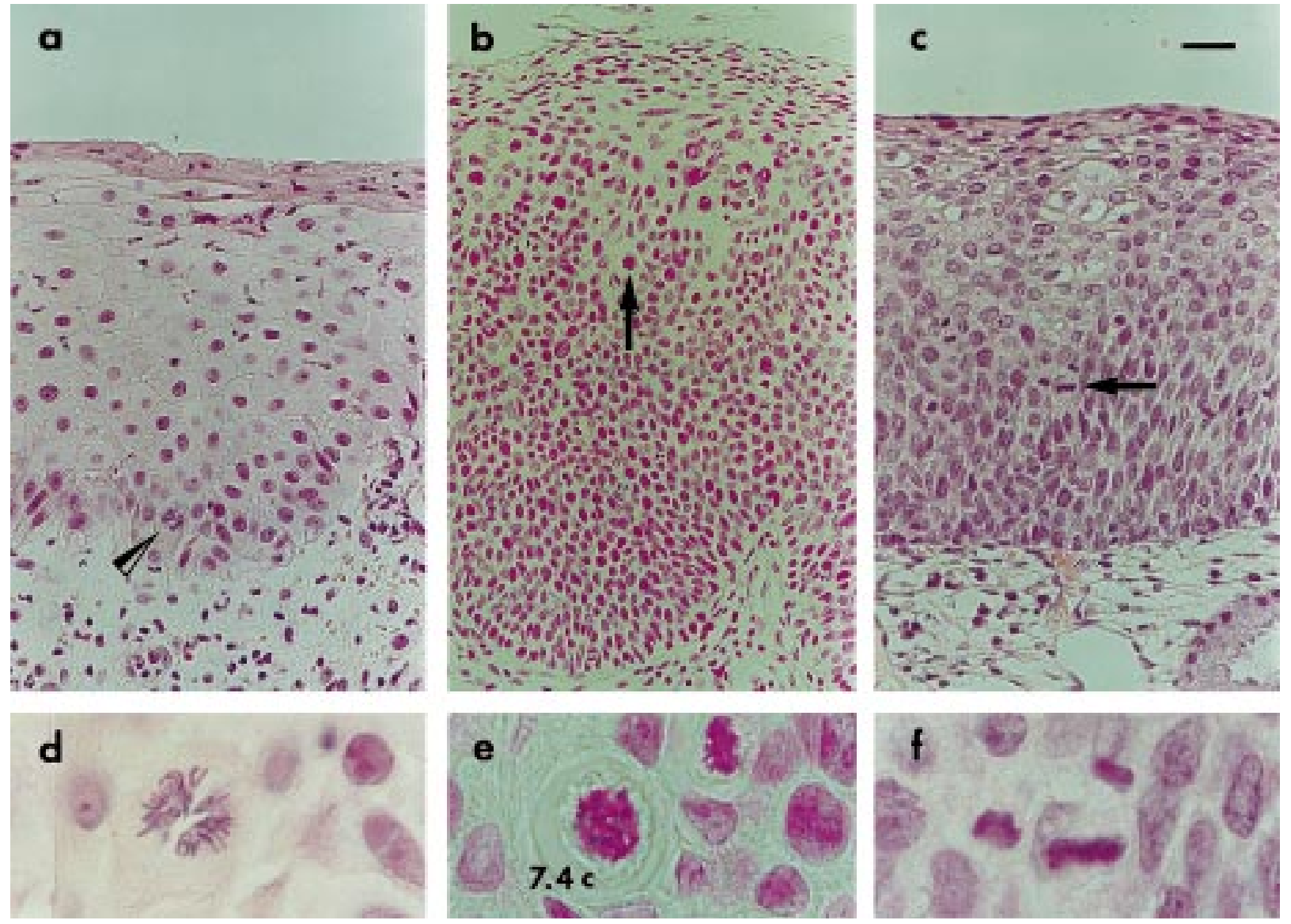

Fig. 1 - Histology of mucous membranes. Inflammation does neither affect genome stability nor tissue order. Division (arrowhead) in inflamed oral mucosa (a) is within the layer of committed cells. High-grade dysplasias (oral mucosa $\mathbf{b}$, and uterine cervix c) show dislocated divisions (arrows) with aberrant DNA content. HE staining of $4 \mu \mathrm{m}$ sections (a, c, d, f). Feulgen staining of $15 \mu \mathrm{m}$ section $(\mathbf{b}, \mathbf{e})$ allowed microphotometry of prophase CDF with $7.4 \mathrm{c}$ DNA. Bar represents $25 \mu \mathrm{m}$ in $\mathbf{a}, \mathbf{c}, 32 \mu \mathrm{m}$ in $\mathbf{b}$, and $10 \mu \mathrm{m}$ in $\mathbf{d}-\mathbf{f}$.
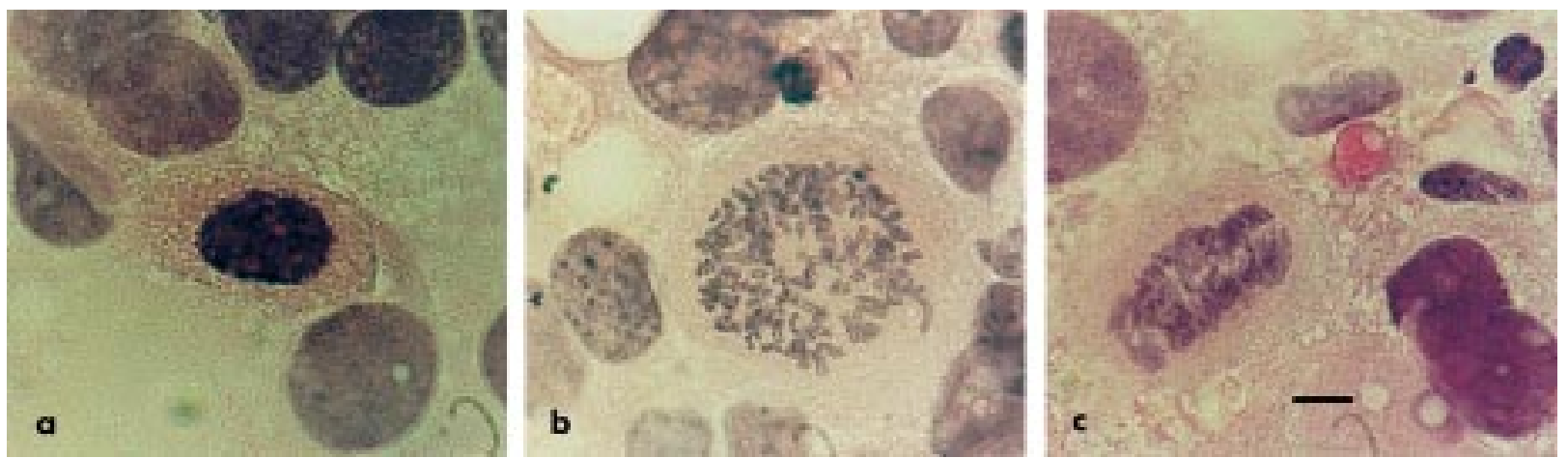

Fig. 2 - Imprint cytology from a breast cancer, stained with HE. After diagnosis, the specimens were destained, Feulgen stained, relocated and analysed for DNA content. Abnormal DNA content recorded with microphotometry: 6.1 c prophase CDF (a), 7.2 c metaphase CDF (b), and $5.2 \mathrm{c}$ anaphase CDF (c). Bar: $10 \mu \mathrm{m}$.

aberrant from $4 \mathrm{c}$ (Steinbeck 1997). The coinage is close to the historical term Kerntheilungsfigur (nuclear division figure) and indicates a pathologic mitosis by definition. CDFs comprise deleterious chromosomal sets with aberrant DNA content as well as the minor fraction characterized by multi- 
polar spindles. The term should emphasize that CDFs are products of chromosome instability. This is in contrast to the concept of true mitosis performing equational bipartition in anaphase as an intrinsic condition of genome stability. In support of these arguments, CDFs were found to precede aneuploidy in interphase nuclei (Steinbeck, 1998 a).

\section{Quantifying CDFs in solid tumours}

Reliable DNA measurements with the aid of an image microphotometer depend on integer nuclei, which can be traced in $15 \mu \mathrm{m}$ sections of surgical specimens. Calibration may be done on interphase nuclei of small lymphocytes providing an endogenous 2 c DNA standard (Steinbeck et al., 1999). DNA data from lesions in bacterially induced inflammations, high-grade dysplasias (HGD) and carcinomas were recorded from oral and colon mucosae (Fig. 3).

Nuclear divisions from inflammations appeared mitotic, i.e. close to or slightly below $4 \mathrm{c}$ DNA. Since telophases require ample space for chromosome transport, they may be underestimated due to knife artefacts. However, divisions clearly above $4 \mathrm{c}$ were obtained from HGD in mucous membranes, while $\mathrm{CDFs}$ in carcinomas averaged above $5 \mathrm{c}$ DNA. A careful investigation of telophase CDFs revealed that their "halves" are generally unbalanced in HGD and in carcinomas (Fig. 2 c). A low incidence of asymmetric telophases characterized the onset of tumorigenesis. Cellular selection suppresses underweighted telophase CDFs during tumour progression. Thus, over-weighted (> $4.5 \mathrm{c}$ ) CDFs accumulate in HGD and carcinomas. Predominant overweight has also been recorded from interphase analyses in carcinomas (Caspersson et al., 1960; Atkin, 1962; Sandritter and Fischer, 1962). These reports are supported by experience from routine pathology that a diploid carcinoma has never developed from aneuploid nuclei in HGD or cancer.

Subtle aberrations in unbalanced telophases as well as in prophase and metaphase CDFs demand instruments sensitive for a DNA content in the femtogram range. Modern image microphotometry is a convenient survey tool to quantify chromosome in/stability in individual nuclei of solid tumours. However, aberrations correlated with DNA amounts equivalent to a mean chromosome $( \pm 0.04 \mathrm{c})$ are at the limits of microphotometry and demand more expensive techniques using molecular probes.

\section{Endomitosis and endoreplication}

The definition of endomitosis comprises two criteria: (1) the nuclear membrane does not dissolve during (2) condensation of chromosomes. The DNA content may amount to $4 \mathrm{c}, 8 \mathrm{c}, 16 \mathrm{c}$, and so on. Thus, the persistent nuclear membrane discriminates endomitoses from mitotic divisions and from CDFs. The sister chromatids eventually separate from endometaphase to endoanaphase without a spindle, leading to a polyploid morphology. Endomitoses can be found in malignant, aneuploid tumours. Sandberg (1990, there Figure 300) has shown rare examples with high DNA content (at least $64 \mathrm{c}$ ). Actual nuclear divisions and consecutive cytokineses have not yet been confirmed with such giant CDFs in human tissues. This cannot be expected seriously, if spindle function is released.

DNA endoreplication does not end up with endomitosis in any case, but may be executed by nuclei in permanent interphase. Such an enlarged interphase nucleus showed $106.5 \mathrm{c}$ in a case of HGD in uterine cervix (Fig. 4). Some dysplastic nevi in human skin harbour overweight interphase nuclei. The distribution profile of their DNA content extends from $2 \mathrm{c}$ up to $10 \mathrm{c}$ and more. The aneuploid condition is obviously caused by incomplete endoreplication. The appearance of additional CDFs is linked with final transformation to melanoma.

One has to keep in mind that overweight nuclei do not inevitably represent pathologic aberrations. Distinct DNA endoreduplication occurs in some tissues during normal human development. Cells in the amnion fluid contain some $8 \mathrm{c}$ nuclei. The nuclear DNA content in human megakaryocytes makes usually $16 \mathrm{c}$, and $64 \mathrm{c}$ at maximum (Weste and Penington, 1972). A level of $8 \mathrm{c}$ endoreduplication has also been observed in adult human heart and liver. Nuclei in hypertrophic myocardium attain $32 \mathrm{c}$. In the shocked liver, some $16 \mathrm{c}$ nuclei were observed, but many cells were binucleated (Steinbeck, 1998b). From these instances of regular endoreplication, it is reasonable to conclude that endomitoses and endoreplicated nuclei do not contribute to tumour progression in general.

\section{Gene amplification and rearrangement}

The unknown mechanism of linear addition of gene copies to chromosomal DNA has been termed amplification that contributes to pathologic mitoses at the molecular level. Such supernumerary domains can be shown with artificial banding on 


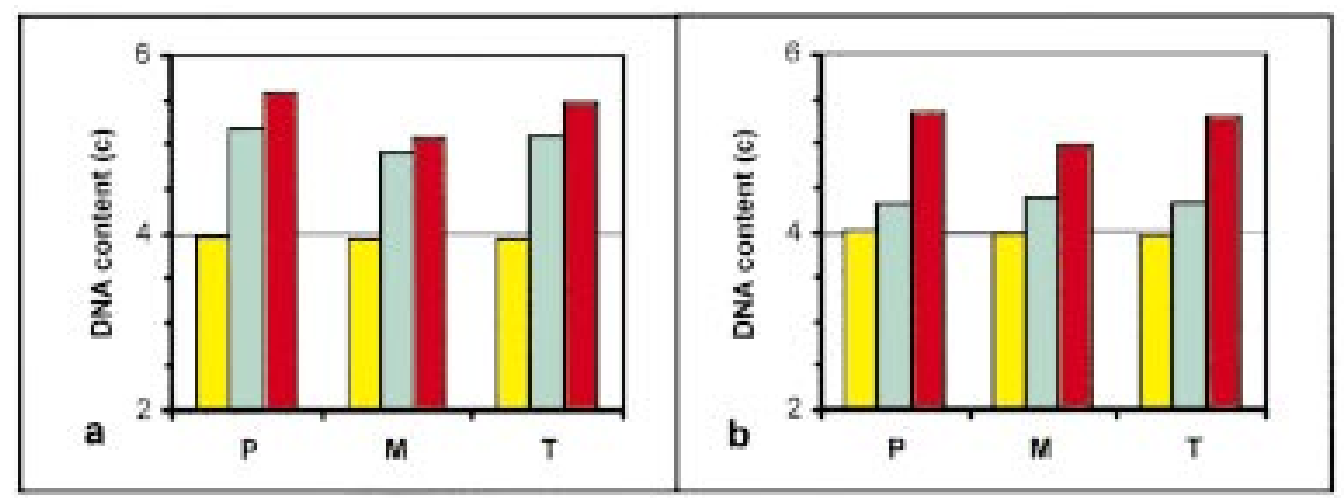

Fig. 3 - DNA content recorded with nuclear divisions in epithelial lesions. In total, 34 cases were investigated with oral mucosae (a) and 65 cases with colon mucosae (b). Divisions from inflammations (yellow: epulis and bacterial colitis) resemble true mitoses as indicated with $4 \mathrm{c}$ calibration lines. High-grade dysplasias (HGD, green) and cases of cancer with poorly differentiated histology (red) deviate from normal mitoses, since their chromosome division figures (CDFs) exceed clearly $4 \mathrm{c}$ DNA. $\mathbf{P}$ prophases (a: 72, 120 and 104, respectively; b: 120, 223, 282). M metaphases (a: 88, 205, 177; b: 150, 210, 211), T telophases (a: 25, 16, 17; b: 52, 65 and 45, respectively).

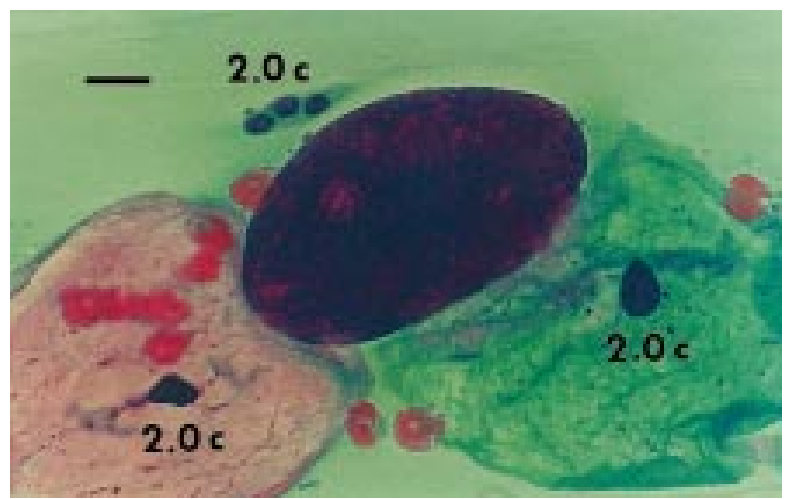

Fig. 4 - Enlarged, endoreplicated nucleus. The 106.5 c DNA content demanded at least 5 replication steps. Three flanking nuclei in $\mathrm{G}_{0}$ at $2 \mathrm{c}$ level. Smear from uterine cervix showing high-grade dysplasia in squamous epithelium. Papanicolaou stain. Bar: $10 \mu \mathrm{m}$.

metaphase spreads from short-term cultures established from biopsies. The microscopic threshold of a heterogeneously staining region (HSR) demands some $15 \mathrm{Mbp}$ with $\mathrm{G}$ banding (Kunze et al. 1996). In human breast cancer, HSR is the prevalent form of DNA amplification. HSRs frequently contain highly multiplied DNA sequences of oncogenes that code for tyrosine kinases, growth factors, transcription factors or other nuclear proteins. A significant association between HSRs and shortened survival has been reported (Bernardino et al., 1998). Genes encoding polypeptides associated with tumour suppressors can also be amplified (Oliner et al., 1992).

If supernumerary sequences do not exceed a HSR threshold, comparative genomic hybridisation (CGH) may detect pathologic gains and losses in

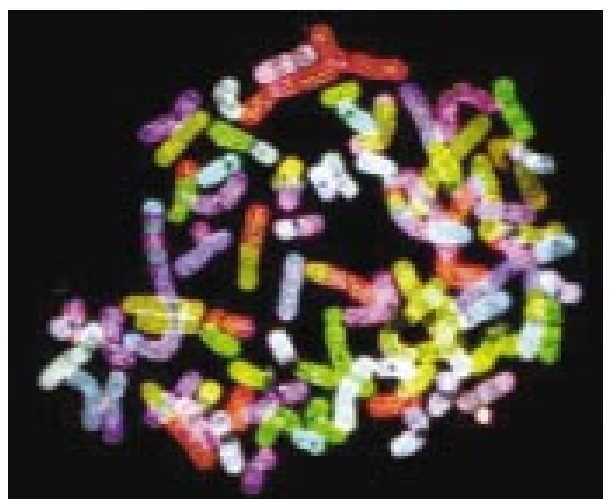

Fig. 5 - SKY of an aneuploid metaphase CDF with multiple chromosome rearrangements. Human breast cancer cell line SKBR3. Courtesy of Dr. Evelin Schröck, Berlin.

genomic DNA from interphase nuclei (Kallionemi et al., 1993). Investigating the same tumour specimens, chromosomal alterations were found well correlated with the frequency of CDFs according to CGH and microphotometry, respectively (Ried et al., 1996; Steinbeck, 1998 c).

Spectral karyotyping (SKY) surpasses the artificial banding techniques and shows readily chromosomal sites as targets of amplification and rearrangements (Schröck et al., 1996, 1997). In contrast to CGH, which is an indirect bulk method, SKY detects directly chromosomal mutations in cell lines or in a patients own metaphase spreads (Fig. 5). This technique is especially helpful when inversions and reciprocal translocations do not alter the genome size. The same is true if deletions are compensated by amplifications. 
The above techniques are precise survey tools to identify pathologic mitoses and eventually faulty interphase nuclei, whereas real-time PCR and microarray assays represent diagnostic aids that focus on tumour relevant genes. Defects caused by point mutations, however, demand sequencing of isolated somatic DNA.

\section{PATHOLOGY OF MITOSIS}

\section{Void cycle checkpoints}

Molecular investigations provide evidence that beside interphase, also prophase throughout telophase are under surveillance. The aberrant DNA content of a CDF, however, indicates that such a cell suffers from genetic alterations and has escaped previous control mechanisms. An asymmetric and successful telophase will deliver immortal progenitors by cytokinesis. Such a final accident may occur in consequence of genetic defects that have not been detected or prosecuted earlier. Apoptosis in coordination with the immune defence protects young and healthy organisms, but an aged person may succumb the risk of somatic cell variation, especially in tumorous processes (Hauschka, 1958; Evan and Vousden, 2001). Crucial to successful anaphase transport is the spindle checkpoint, which controls the correct attachment of kinetochores with bipolar microtubules (Nicklas, 2000; Michel et al., 2001). Defective daughter cells are the product of total duping the cascade of checkpoints and of constitutive anaphase promotion.

Loss of heterozygosity ( $\mathrm{LOH})$ in recessive alleles with tumour suppressing capacities generates inevitably tumours. The tumour suppressor P53 is not only active during G1, but shows a broad responsibility for mitotic control. P53 functions also as a component of a spindle checkpoint (Meek, 2000; Vogelstein et al., 2000). Faulty DNA sequences may persist due to a knockout of the G2 repair machinery. A more conspicuous damage is caused by disorders in sister chromatid separation (Heck, 1997; Michaelis et al., 1997; Rao et al., 2001). These molecular failures become evident in light microscopy from errant chromosomes in metaphase. Histology of premalignant lesions exhibits besides errant elements also chromatin bridges (and breaks) in anaphase and asymmetry in telophase.

\section{Mitotic mistakes and tumorigenesis}

Most frequently, tumorigenesis does not begin with malignancy. Atypical, non-invasive cells pass through progressive stages of dysplasia. Cancers in situ are lesions that are known to become inevitably invasive within a few years, if not treated. Malignant cells are defined in histology by the loss of both, differentiation and local residency. They cross the basement membrane and invade adjacent tissues. Cancer cells may learn to colonize lymph nodes or metastasise other organs (Liotta and Kohn, 2001). Tumour progression deteriorates the cytoplasmic turnover, but affects above all the nucleus. Records of 5\% - 10\% pathologic mitoses in low-grade dysplasias support this view. A continuous increase up to $60 \%$ and $80 \%$ CDFs of total divisions may be found in highgrade dysplasias and cancers, respectively. The frequency of aneuploid interphase nuclei increases in positive correlation with CDFs and chromosomal aberrations detected by $\mathrm{CGH}$.

Interestingly, monosomy in liveborn infants has been established only for chromosome 21 , and even that is extremely rare (Wisniewski et al., 1983). Spontaneous abortion obviously eliminates defective zygotes, whereas tumours are sustained by the host. Ependymomas and meningiomas are frequently characterized by monosomy 22 . Most of them react clinically benigne because of low proliferation. In contrast, their grade-3 variants show enforced proliferation with CDFs and are malignant. Tissues will be unlikely to develop malignant lesions if they show scarce proliferation (Boveri, 1914).

Correct development depends on genes that regulate the need of cell proliferation and apoptosis. Failures in proliferation have been described as sources of genome instability and chromosome mutations resulting in CDFs and interphase aneuploidy. Failures of the apoptotic system may be caused by mutations in the genes coding for AIF, APAF1, P53, P21 and/ or caspases (Soengas et al., 2001; Joza et al., 2001). Mitochondria initiate an alternative death-signalling pathway by releasing cytochrome $\mathrm{c}$ that triggers the cascade of caspases in the cytoplasm (Evan and Vousden, 2001). Factors that increase the cycling frequency of tumour cells will enhance aggressiveness. The Hedgehog protein is a candidate for triggering somatic stem cells, because the respective gene is aberrantly activated in basal-cell carcinomas (Wicking et al., 1999; Taipale and Beachy, 2001). 
CDFs will be accumulated either by an unscheduled proliferation factor or when apoptosis is leaky. Coincidence of both, enhanced proliferation and failed cell death will be most disastrous for the host. Multiple checkpoint overrun is the condition for successful telophase CDFs. An undisturbed chromatin decondensation denotes these nuclei as chips for clonal selection in tumour progression.

\section{CONCLUSION}

Pathology of mitosis means proliferation in vivo through CDFs, which have not been eliminated by apoptosis. CDFs must take advantage of constitutive anaphase transport followed by chromatin decondensation, to be effective in the next cell generation. Genome instability evokes frequently chromosome instability in premalignant tumours (dysplasias). Thus, CDFs persist by override of cell-cycle checkpoints and are the source of aneuploid interphase nuclei in dysplasias and cancers. CDFs are generated stochastically by mitotic faults; they survive and supersede an autochthonous cell compartment. This process takes place at the host's expense and is understood as a series of clonal selections. The pathology of premalignant and malignant tumours is the given homeland for the pathology of mitosis.

\section{REFERENCES}

Atkin N.: The relationship between the deoxyribonucleic acid content and the ploidy of human tumours. Cytogenetics 1 , 113-122, 1962.

Atkin N.B., and Richards B.M.: Deoxyribonucleic acid in human tumours as measured by microspectrophotometry of Feulgen stain: A comparison of tumours arising at different sites. Brit. J. Cancer 10, 769-786, 1956.

Barry M., Sinha S.K., Leader M.B., and Kay E.W.: Poor agreement in recognition of abnormal mitoses: requirement for standardized and robust definitions. Histopathol. 38, 6872, 2001.

Bernardino J., Gerbault-Seureau M., Zafrani B., Dericke Y., Boudou E., Magdelenat H., and Dutrillaux B.: Homogeneously staining regions in 223 breast carcinomas: Cytogenetic and clinicopathological correlations. Brit. J. Cancer 78, 12141218, 1998.

Böcking A.: Abklärung plattenepithelialer Dysplasien mittels DNA-Bildzytometrie. Dt. Ärztebl. 95, A-658-662, 1998.

Boveri T.: Zur Frage der Entstehung maligner Tumoren. G. Fischer, Jena, 1914.
Caspersson O.: Quantitative cytochemical studies on normal, malignant, premalignant and atypical cell populations from the human uterine cervix. Acta Cytol. 8, 45-60, 1964.

Caspersson T., Lomakka G., Svensson G., and Säfström R.: A versatile ultramicrospectrograph for multiple-line and surface scanning high resolution measurements employing automatized data analysis. Exp. Cell Res. 3, 40-51, 1955.

Caspersson T., Lomakka G., and Caspersson O.: Quantitative cytochemical methods for the study of tumor cell populations. Biochem. Pharmacol. 4, 113-127, 1960.

Caspersson T., Zech L., and Johansson C.: Differential banding of alkylating fluorochromes in human chromosomes. Exp. Cell Res. 60, 315-319, 1970.

Deeley E.M.: An integrating microdensitometer for biological cells. J. Sci. Instru. 32, 263-267, 1955.

Evan G.I., and Vousden K.H.: Proliferation, cell cycle and apoptosis in cancer. Nature 411, 342-348, 2001.

Flemming W.: Beiträge zur Kenntnis der Zelle und ihrer Lebenserscheinungen. Arch. Mikrosk. Anat. 16, 302-436, 1879.

Galeotti G.: Beitrag zum Studium des Chromatins in den Epithelzellen der Carcinome. Beiträge Pathol. Anat. Allg. Pathol. 14, 249-271, 1893.

Hamperl H., Kaufmann C., and Ober K.: Histologische Untersuchungen an der Cervix schwangerer Frauen: Die Erosion und das Carcinoma in situ. Arch Gynäkol 184, 181-280, 1954.

Hansemann D.: Ueber asymmetrische Zelltheilung in Epithelkrebsen und deren biologische Bedeutung. Arch. Path. Anat. Physiol. Klin. Med. 119, 299-326, 1890.

Hauschka T.S.: Correlation of chromosomal and physiologic changes in tumors. In Symposium on genetic approaches to somatic cell variation (Ed. Oak Ridge National Lab.) Wistar Institute, Philadelphia, pp. 197-233, 1958.

Heck M.M.S.: Condensins, cohesins, and chromosome architecture: How to make and break a mitotic chromosome. Cell 91, 5-8, 1997.

Joza N., Susin S., Daugas E., et al., and Penninger J.M.: Essential role of the mitochondrial apoptosis-inducing factor in programmed cell death. Nature 410, 549-554, 2001.

Kallioniemi O.P., Kallioniemi A., Sudar D., Rutovitz D., Gray J.W., Waldman F., and Pinkel D.: Comparative genomic hybridization: A rapid new method for detecting and mapping DNA amplification in tumors. Semin. Cancer Biol. 4, 41-46, 1993.

Khaled A., Imamura Y., Noriki S., and Fukuda M.: Early progression stage of malignancy of uterine cervical dysplasia as revealed by immunohistochemical demonstration of increased DNA-instability. Eur. J. Histochem. 44, 143-156, 2000.

Koller P.C.: Abnormal mitosis in tumours. Brit. J. Cancer 1, 38-46, 1947.

Kunze B., Weichenhan D., Virks P., Traut W., and Winking H.: Copy numbers of a clustered long-range repeat determine C-band staining. Cytogenet. Cell Genet. 73, 86-91, 1996. 
Liotta L.A., and Kohn E.C.: The microenvironment of the tumour-host interface. Nature 411, 375-3379, 2001.

Meek D.W.: The role of p53 in the response to mitotic spindle damage. Pathol. Biol., Paris 48, 246-254, 2000.

Michaelis C., Ciosk R., and Nasmyth K.: Cohesins: Chromosomal proteins that prevent premature separation of sister chromatids. Cell 91, 35-45, 1997.

Michel L.S., Liberal V., Chatterjee A., Kirchwegger R., et al., and Benezra R.: MAD2 haplo-insufficiency causes premature anaphase and chromosome instability in mammalian cells. Nature 409, 355-359, 2001.

Nicklas R.B.: Chromosomes in mitosis: chance and checkpoint. In Chromosomes Today, vol 13. (Eds. Olmo E., and Redi C.A.) Basel, Boston, Berlin: Birkhäuser, pp 73-78, 2000.

Oliner J.D., Kinzler K.W., Meltzer P.S., George D.L., and Vogelstein B.: Amplification of a gene encoding a p53-associated protein in human sarcomas. Nature 358, 80-83, 1992.

Pihan G.A., Purohit A., Wallace J., Knecht H., Woda B., Quesenberry P., and Doxsey S.J.: Centrosome defects and genetic instability in malignant tumors. Cancer Res. 58, 3974-3985, 1998.

Politzer G.: Pathologie der Mitose. Protoplasma-Monographien, Bd 7. Borntraeger, Berlin, 1934.

Rao H., Uhlmann F., Nasmyth K., and Varshavsky A.: Degradation of a cohesin subunit by the N-end rule pathway is essential for chromosome stability. Nature 410, 955-959, 2001.

Richards B.M., and Atkin N.B.: The differences between normal and cancerous tissues with respect to the ratio of DNA content to chromosome number. Acta Unio Intern. contra Cancrum 16, 124-128, 1960.

Ried T., Knutzen R., Steinbeck R., Blegen H., Schröck E., Heselmeyer K., Du Manoir S., and Auer G.: Comparative genomic hybridization reveals a specific pattern of chromosomal gains and losses during the genesis of colorectal tumors. Genes Chromosomes Cancer 15, 234-245, 1996.

Roux W.: Ueber die Bedeutung der Kerntheilungsfiguren: Eine hypothetische Erörterung. W. Engelmann, Leipzig, 1883.

Sandberg A.A.: The chromosomes in human cancer and leukemia. 2nd ed. Elsevier, Amsterdam, 1990.

Sandritter W., and Fischer R.: Der DNS-Gehalt des Normalen Plattenepithels, des Carcinoma in situ und des Invasiven Carcinoms der Portio. In Proceedings of the first internatl congress of exfoliate cytology. Vienna, Austria, 1961. Philadelphia: Lippincott, Philadelphia, pp. 189-195, 1962.

Schrock E., du Manoir S., Veldman T., Schoell B., Wienberg J., Ferguson-Smith MA., Ning Y., Ledbetter D.H., Bar-Am I., Soenksen D., Garini Y., and Ried T.: Multicolor spectral karyotyping of human chromosomes. Science 273, 494-497, 1996.

Schrock E., Veldman T., Padilla-Nash H., Ning Y., Spurbeck J., Jalal S., Shaffer L.G., Papenhausen P., Kozma C., Phelan M.C., Kjeldsen E., Schonberg S.A., O’Brien P., Biesecker L., du Manoir S., and Ried T.: Spectral karyotyping refines cytogenetic diagnostics of constitutional chromosomal abnormalities. Hum. Genet. 101, 255-262, 1997.
Soengas M.S., Capodieci P., Polsky D., et al., and Lowe S.W.: Inactivation of the apoptosis effector Apaf-1 in malignant melanoma. Nature 409, 207-211, 2001.

Steinbeck R.G.: Atypical mitoses in lesions of the oral mucosa: a new interpretation of their impact upon tumorigenesis. Oral Oncol. 33, 110-118, 1997.

Steinbeck R.G.: The DNA content of chromosome division figures and interphase nuclei classifies ulcerative colitis. Eur. J. Cancer 34, 175-181, 1998a.

Steinbeck R.G.: Mitotic failure and genome stability in benign, premalignant and malignant human tissues. Karolinska, Stockholm, 1998b.

Steinbeck R.G.: Chromosome division figures reveal genomic instability in tumorigenesis of human colon mucosa. Brit. J. Cancer 77, 1027-1033, 1998c.

Steinbeck R.G., Auer G.U., and Zetterberg A.D.: Reliability and significance of DNA measurements in interphase nuclei and division figures in histological sections. Eur. J. Cancer 35, 787-795, 1999.

Steinbeck R., and Auer G.: Genome instability in human tumorigenesis: Microphotometry of interphase nuclei and pathologic mitoses reveals dysplasia. Eur. J. Histochem. 44, 133-142, 2000.

Stern C.: The nucleus and somatic cell variation. In Symposium on genetic approaches to somatic cell variation (Ed. Oak Ridge National Lab.) Wistar Institute, Philadelphia, pp. 1-34, 1958.

Sturtevant A.H.: The linear arrangement of six sex-linked factors in Drosophila as shown by their mode of association. J. Exp. Zool. 14, 43-59, 1913.

Taipale J., and Beachy P.A.: The Hedgehog and Wnt signaling pathways in cancer. Nature 411, 349-354, 2001.

Therman E., and Timonen S.: Multipolar spindles in human cancer cells. Hereditas 36, 393-405, 1950.

Tjio J.H., and Levan A.: The chromosome number in man. Hereditas 42, 1-6, 1956.

Van der Ploeg M.: Cytochemical nucleic acid research during the twentieth century. Eur. J. Histochem. 44, 7-42, 2000.

Vogelstein B., Lane D., and Levine A.J.: Surfing the p53 network. Nature 408, 307-310, 2000.

Weste S.M., and Penington D.G.: Fluorometric measurement of DNA in bone marrow cells: The measurement of megakaryocyte DNA. J. Histochem. Cytochem. 20, 627-633, 1972.

Wicking C., Smyth I., and Bale A.: The hedgehog signalling pathway in tumorigenesis and development. Oncogene 18, 7844-7851, 1999.

Wisniewski K., Dambska M., Jenkins E.C, et al.: Monosomy 21 syndrome: Further delineation including clinical, neuropathological, cytogenetic and biochemical studies. Clin. Genet. 23, 102-110, 1983.

Zhang D., and Nicklas R.B.: 'Anaphase' and cytokinesis in the absence of chromosomes. Nature 382, 466-468, 1996. 